\title{
Perancangan Sistem Informasi Tracerstudy Menggunakan Aplikasi Open Source Di Universitas
}

\author{
Ridwan Raafi'Udin*1, Catur Nugrahaeni Pustpita Dewi², Bayu Hananto ${ }^{3}$ \\ ${ }_{1,2,3}$ Fakultas Ilmu Komputer, Universitas Pembangunan Nasional Veteran Jakarta \\ "11 raafiudin@gmail.com,${ }^{2}$ catur.nugrahaeni@gmail.com, ${ }^{3}$ bayu.hananto86@gmail.com
}

\begin{abstract}
Abstrak-- Keberhasilan alumni di dunia kerja atau industri menjadi salah satu tolak ukur keberhasilan perguruan tinggi dalam mendidik dan menghasilkan lulusannya. Untuk mengetahui keberhasilan para alumni maka dibutuhkan suatu sistem yang dapat menarik data dari perusahaan tempat alumni bekerja dan dari alumni itu sendiri. Cara konvensional dengan membagikan kuisioner berbasis kertas dan/ atau mengunjungi perusahaan dirasa kurang efektif karena membutuhkan waktu dan biaya yang banyak. Kemajuan teknologi memberikan suatu jalan atau cara yang lebih mudah dan murah namun membutuhkan pengetahuan di bidang teknologi informasi dan komunikasi terutama di bidang keterampilan komputer. Pada penelitian ini, peneliti mencoba meng-alih mediakan kuisioner konvensional menjadi suatu sistem yang disebut sistem aplikasi tracer study berbasis web. Dengan menggunakan aplikasi yang berbasis web dan internet diharapkan penyampaian dan pengumpulan kuisioner menjadi lebih mudah, cepat, dan murah. Dengan terkumpulnya data yang sebanyak-banyaknya memungkinkan perhitungan dan perkiraan keberhasilan alumni semakin akurat. Dengan data keberhasilan alumni yang akurat maka universitas dapat menggunakan data tersebut sebagai acuan dalam menentukan perbaikan atau peningkatan dalam berbagai sektor di dalam tubuh universitas itu sendiri. Dengan peningkatan yang berlandaskan pada data tracerstudy diharapkan pengembangan universitas akan lebih diterima oleh seluruh stakeholder.
\end{abstract}

\section{Kata Kunci-Tracerstudy, Manajemen data alumni}

\section{Pendahuluan}

Informasi merupakan bagian yang sangat penting di era saat ini, dimana informasi ini sudah sangat mudah kita dapatkan dari berbagi media diantaranya media kertas, gambar, suara dan media online. Dengan berbagi media tersebut kini masyarakat sudah sangat mudah mengetahui informasi yang ada baik di dalam dan luar negeri. Infomasi harus dikelola secara sistematis dan terdokumentasi dalam suatu sistem.

Tracer Study merupakan suatu metode yang digunakan suatu perguruan tinggi dalam memperoleh data alumni. Tracer study bertujuan untuk mengetahui hasil pendidikan dalam bentuk transisi dari duni pendidikkan tinggi ke dunia industri serta informasi tentang penggalian lebih lanjut terhadap informasi lulusan.

Alumni merupakan salah satu tolak ukur tingkat keberhasilan pendidikan pada suatu perguruan tinngi. Kualitas institusi pendidikan yang dinilai dari alumni berupa lama tunggu alumni untuk mendapatkan pekerjaan. Semakin cepat alumni memperoleh pekerjaan maka kualitas alumni akan semakin baik. Tentu dengan nilai perolehan pendapatan gaji yang standar, serta relevansi bidang pekerjaan dengan bidang keilmuan yang diambil ketika menempuh pendidikan.

Dari permasalahan diatas dapat dibentuk suatu rancangan aplikasi yang dapat menyajikan informasi mendalam dan rinci mengenai kecocokan kerja, baik secara horizontal (antar berbagai bidang ilmu) maupun vertikal (antar berbagi level/strata pendidikan). Hasil dari penelitian ini akan menghasilkan suatu perancangan sistem innformasi tracer study yang dapat ikut membantu mengatasi permasalahan kesenjangan kesempatan kerja dan upaya perbaikannya terhadap alumni yang ada di suatu universitas.

Dengan pemanfaatan sistem informasi tersebut, maka suatu universitas dapat lebih mudah memperoleh informasi mengenai kompetensi yang relevan bagi dunia kerja danaupaya perbaikannya. Di sisi lain dunia industri dan dunia kerja dapat melihat informasi ke dalam institusi pendidikan tinggi melalui tracer study, dan dengan demikian dapat menyiapkan diri dengan menyediakan pelatihan-pelatihan yang lebih relevan bagi lulusan pencari kerja.

Berdasarkan latar belakang diatas, maka peneliti mengidentifikasi masalah yang terdapat pada perancangan sistem informasi tracerstudy antara lain belum maksimalnya sosialisasi tracer study kepada alumni dan kurangnya pemahaman tentang tracer study dari alumni dan perusahaan tempat bekerja.

Penelitian ini dilaksanakan terhadap proses bisnis yang terdapat pada aplikasi tracerstudy di lingkungan universitas yang diteliti. Merancang sistem informasi terintegrasi menggunakan pendekatan SDLC (System Development Life Cycle).

Tujuan dari penelitan ini antara lain :

- Memberikan kemudahan dalam proses pencarian data alumni.

- Mengetahui perkembangan alumni serta kecenderungan terhadap pekerjaan, pendapatan dan aspek lainnya. 
- Dapat membantu niversitas dalam proses perkembangan kurikulum yang sesuai di dunia kerja

Manfaat yang diperoleh dari penelitan ini antara lain :

- Memudahkan pimpinan mengetahui informasi tentang keberhasilan alumni.

- Perusahaan dapat mengetahui kualitas alumni dari suatu perguruan tinggi

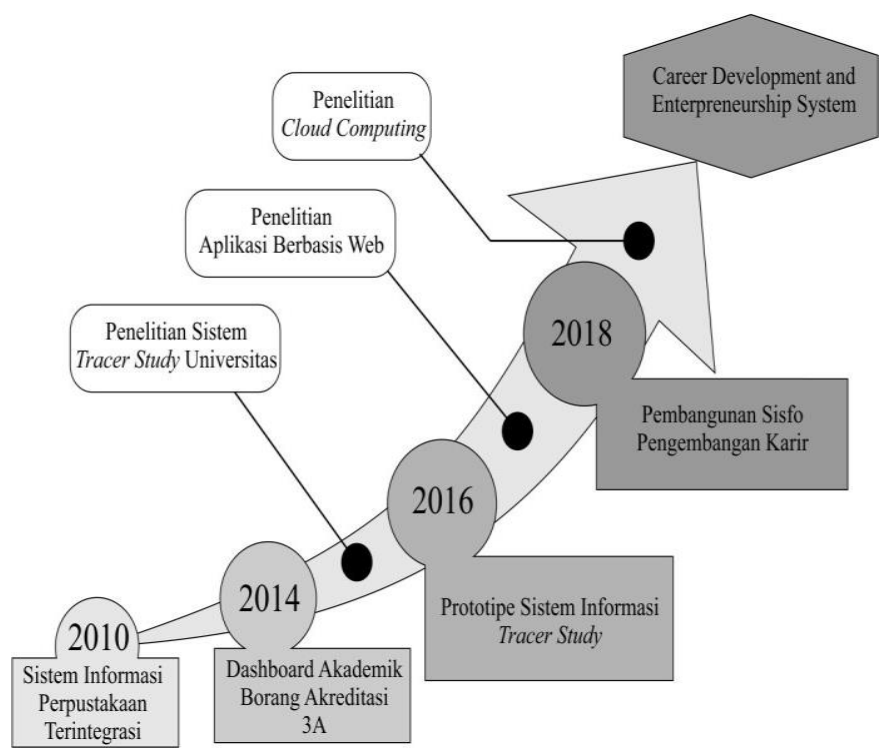

Gambar 1.Roadmap Penelitian

\section{Metode PENELITIAN}

\section{A. Rancangan Penelitian}

Penelitian ini dilaksanakan dengan berbagai tahapan yang terdiri dari pencarian data dan pengolahan, sebagai berikut :

\section{1) Persiapan dan identifikasi masalah}

Pada tahapan ini dilaksanakan persiapan dan identifikasi masalah yang terjadi pada proses bisnis yang terdapat pada sistem informasi tracer study.

\section{2) Pengumpulan Data}

Pengumpulan data atau informasi yang diperoleh pada penelitian ini berasal dari data primer. Untuk data primer, teknik pengumpulan data dilakukan dengan wawancara dan observasi lapangan. Wawancara dilakukan kepada pihak yang terkait, diantaranya alumni, pimpinan universitas, pihak perusahaan, dan pengelola sistem.

\section{3) Perancangan dan Pembangunan Aplikasi}

Dalam perancangan sistem informasi terintegrasi yang dilakukan peneliti, dibutuhkan analisa rancangan terhadap dokumen dan kebutuhan pengguna yang sesuai dengan kebutuhan proses bisni. Dengan demikian hasil dari perancangan ini dapat digunakan sebagai skema pembuatan prototipe aplikasi.

\section{4) Aplikasi Tracerstudy}

Tidaklah terbatas pada perguruan tinggi saja, tetapi lebih jauh lagi dapat memberikan informasi penting mengenai hubungan (link) antara dunia pendidikan tinggi dengan dunia kerja. Tracer study dapat menyajikan informasi mendalam dan rinci mengenai kecocokan/match kerja baik horisontal (antar berbagai bidang ilmu) maupun vertikal (antar berbagai level/strata pendidikan). Dapat ikut membantu mengatasi permasalahan kesenjangan kesempatan kerja dan upaya perbaikannya. Bagi universitas, informasi mengenai kompetensi yang relevan bagi dunia kerja dapat membantu upaya perbaikan kurikulum dan sistem pembelajaran. Di sisi lain, dunia industri dan dunia kerja dapat "melongok" ke dalam instistusi pendidikan tinggi melalui tracerstudy, dan dengan demikian dapat menyiapkan diri dengan menyediakan pelatihan-pelatihan yang lebih relevan bagi sarjana pencari kerja baru.

\section{5) Pelatihan dan Evaluasi}

Pada tahapan ini dilaksanakan pengenalan dan pelatihan penggunaan aplikasi terhadap alumni, dan operator di tingkat universitas dan fakultas. Selanjutnya dilaksanakan evaluasi oleh pengguna terhadap sistem dari segi tampilan, data, kemudahan penggunaan, serta evaluasi tingkat manfaat oleh pengguna.

\section{6) Laporan dan Publikasi}

Akhir dari penelitian ini dilakukan seminar terhadap pengguna, pembuatan laporan, dan publikasi ilmiah melalui penerbitan jurnal.

\section{B. Alur Penelitian}

Alur penelitian ditunjukan dengan diagram fish bone di bawah ini :

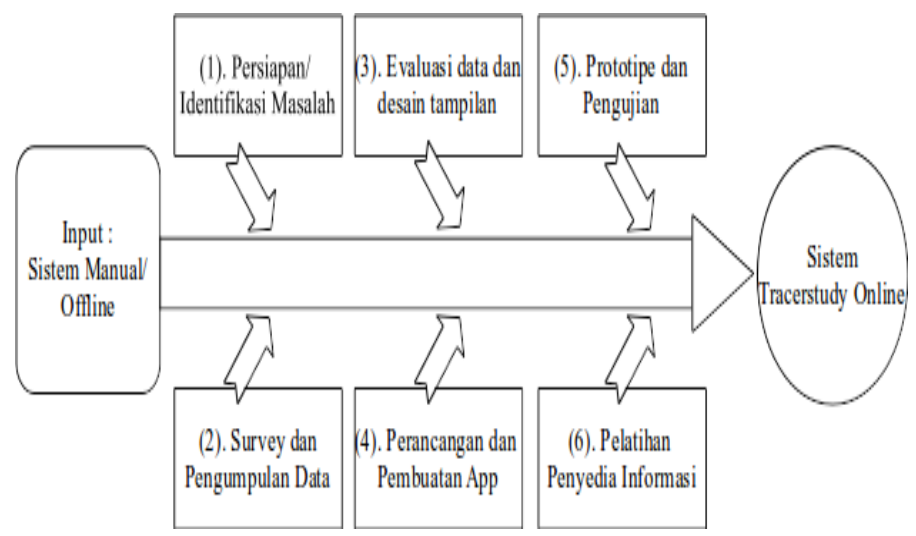

Gambar 1. Alur Penelitian

\section{HASIL DAN PEMBAHASAN}

Pada tahapan analisa dilaksanakan dan didokumentasikan menggunakan UML. Analisa yang dilaksanakan terhadap sistem tracerstudy yang sedang berjalan saat ini, dan hasil analisa pengembangan yang terdapat pada penelitian ini. Adapun hasil analisanya sebagai berikut : 


\section{A. Hasil Analisa}

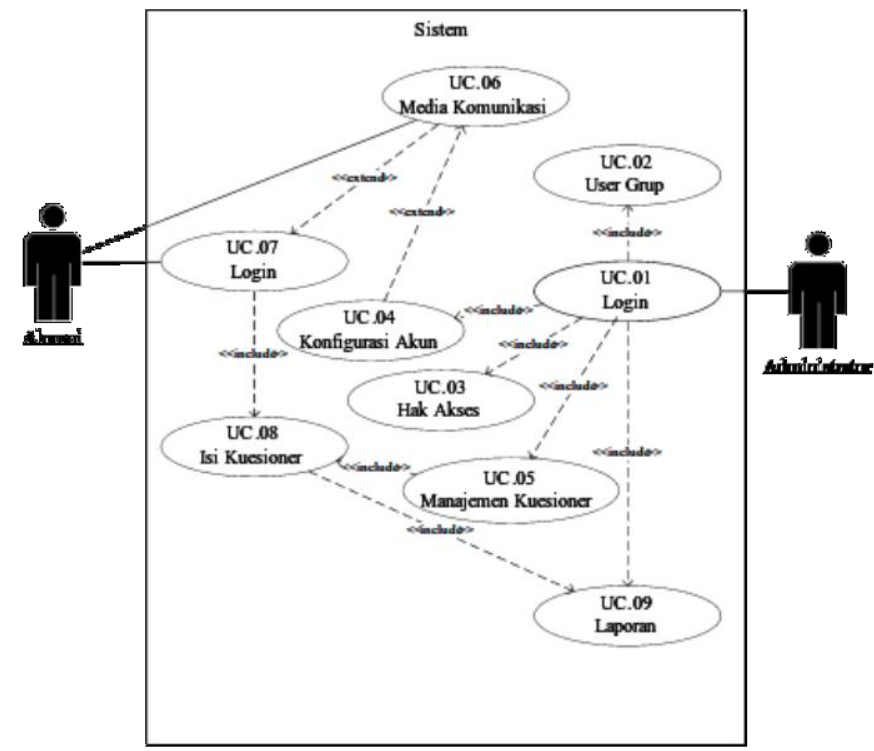

Gambar 2. Use Case Diagram Pengembangan

Use case diagram tersebut menjelaskan tentang hasil pengembangan sistem aplikasi untuk manajemen tracerstudy pada penelitian ini. Penjelasan lebih lanjut dideskripsikan dalam tabel berikut :

Tabel 1. Deskripsi Use Case Diagram

\begin{tabular}{|c|c|c|}
\hline $\mathrm{No}$ & Use Case & Deskripsi \\
\hline UC.01 & Login & $\begin{array}{l}\text { Untuk masuk ke dalam } \\
\text { aplikasi Tracer Study } \\
\text { Administrator wajib untuk } \\
\text { Login terlebih dahulu, } \\
\text { untuk masuk ke halaman } \\
\text { Administrator berbasis } \\
\text { Dekstop. }\end{array}$ \\
\hline UC.02 & User Grup & $\begin{array}{l}\text { Use case ini diakses oleh } \\
\text { Administrator. Untuk } \\
\text { mengkonfigurasi User } \\
\text { Grup. }\end{array}$ \\
\hline UC.03 & Hak Akses & $\begin{array}{l}\text { Use case ini diakses oleh } \\
\text { Administrator. Untuk } \\
\text { mengkonfigurasi Hak } \\
\text { Akses dari User Grup, User } \\
\text { Grup mana saja yang } \\
\text { berhak untuk mengakses } \\
\text { menu pada Aplikasi Tracer } \\
\text { Study. }\end{array}$ \\
\hline UC.04 & $\begin{array}{c}\text { Konfigurasi } \\
\text { Akun }\end{array}$ & $\begin{array}{l}\text { Use case ini diakses oleh } \\
\text { Administrator. Untuk } \\
\text { mengkonfigurasi Akun. } \\
\text { User mana saja yang } \\
\text { termasuk User Grup. }\end{array}$ \\
\hline UC.05 & Manajemen & Use case ini diakses oleh \\
\hline
\end{tabular}

\begin{tabular}{|c|c|c|}
\hline & Kuesioner & $\begin{array}{l}\text { Administrator. Untuk } \\
\text { Manajemen Kuesioner. }\end{array}$ \\
\hline UC.06 & $\begin{array}{c}\text { Media } \\
\text { Komunikasi }\end{array}$ & $\begin{array}{l}\text { Use case ini diakses oleh } \\
\text { Administrator. Untuk } \\
\text { memberikan informasi } \\
\text { melalui Media Komunikasi, } \\
\text { media komunikasi yang } \\
\text { digunakan antara lain : } \\
\text { 1. Surat Elektronik } \\
\text { (SUREL) } \\
\text { 2. SMS } \\
\text { 3. Telepon } \\
\text { 4. Sosial Media }\end{array}$ \\
\hline UC.07 & Login & $\begin{array}{l}\text { Untuk masuk ke dalam } \\
\text { aplikasi Tracer Study } \\
\text { Alumni wajib untuk Login } \\
\text { terlebih dahulu, untuk } \\
\text { masuk ke halaman Alumni } \\
\text { berbasis Web. }\end{array}$ \\
\hline UC.08 & Isi Kuesioner & $\begin{array}{l}\text { Use case ini diakses oleh } \\
\text { Alumni setelah berhasil } \\
\text { Login. Untuk mengisi } \\
\text { kuesioner yang telah } \\
\text { disediakan oleh } \\
\text { Administrator. }\end{array}$ \\
\hline UC.09 & Laporan & $\begin{array}{l}\text { Use case ini diakses oleh } \\
\text { Administrator. Untuk } \\
\text { melihat siapa saja alumni } \\
\text { yang sudah mengisi } \\
\text { kuesioner. }\end{array}$ \\
\hline
\end{tabular}

\section{B. Hasil Perancangan}

Pada tahapan perancangan didokumentasikan dalam bentuk Activity Diagram.

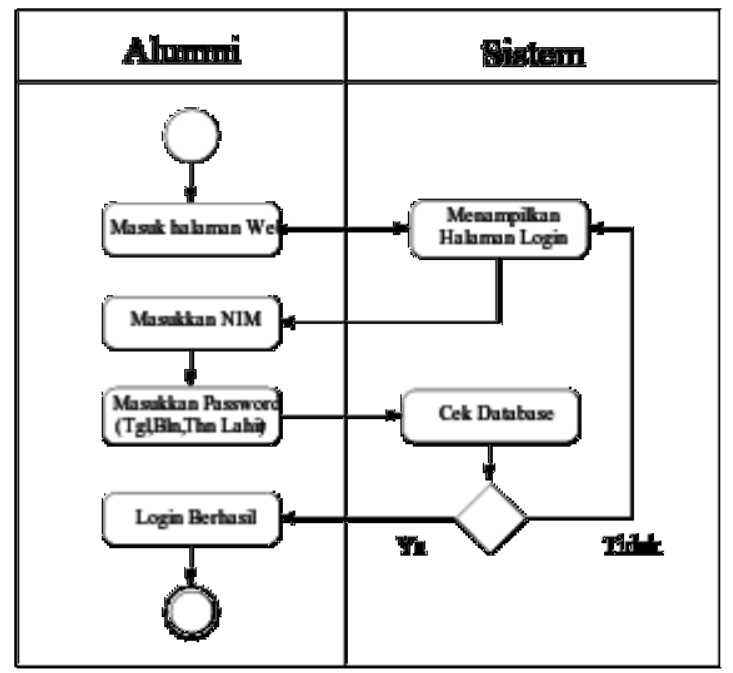

Gambar 3. Activity Login Administrator 


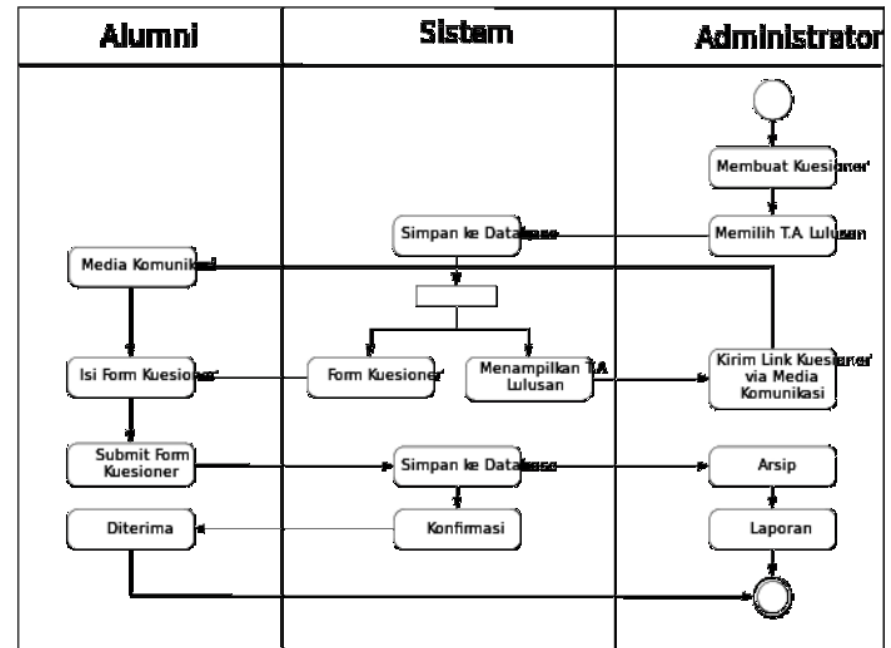

Gambar 4. Activity Kuesioner

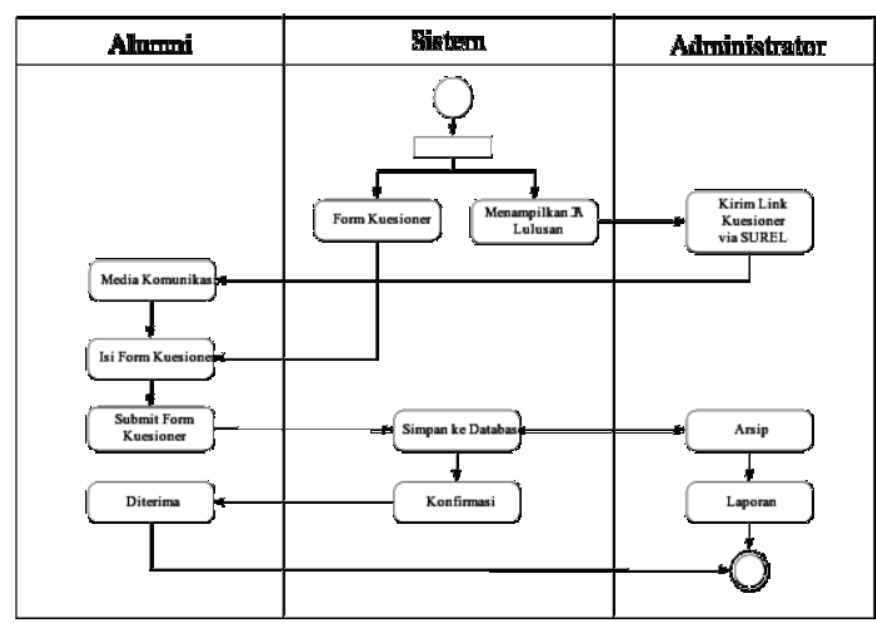

Gambar 5. Activity Media Komunikasi

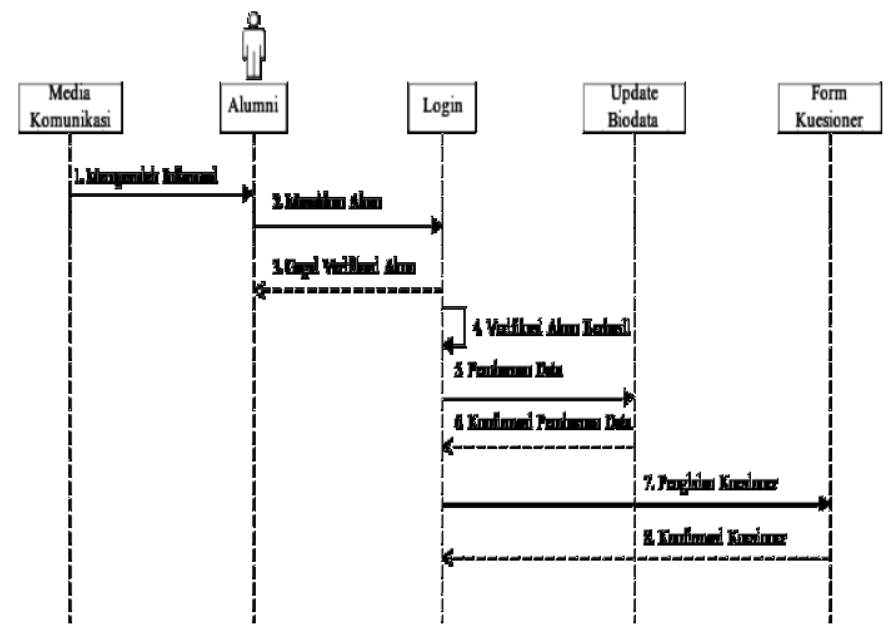

Gambar 6. Sequence Diagram Alumni

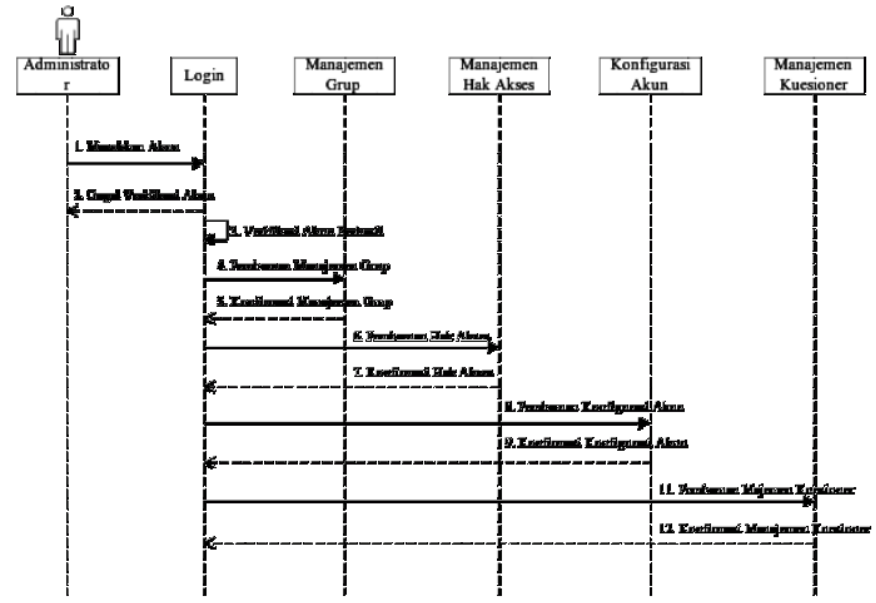

Gambar 7. Sequence Diagram Administrator

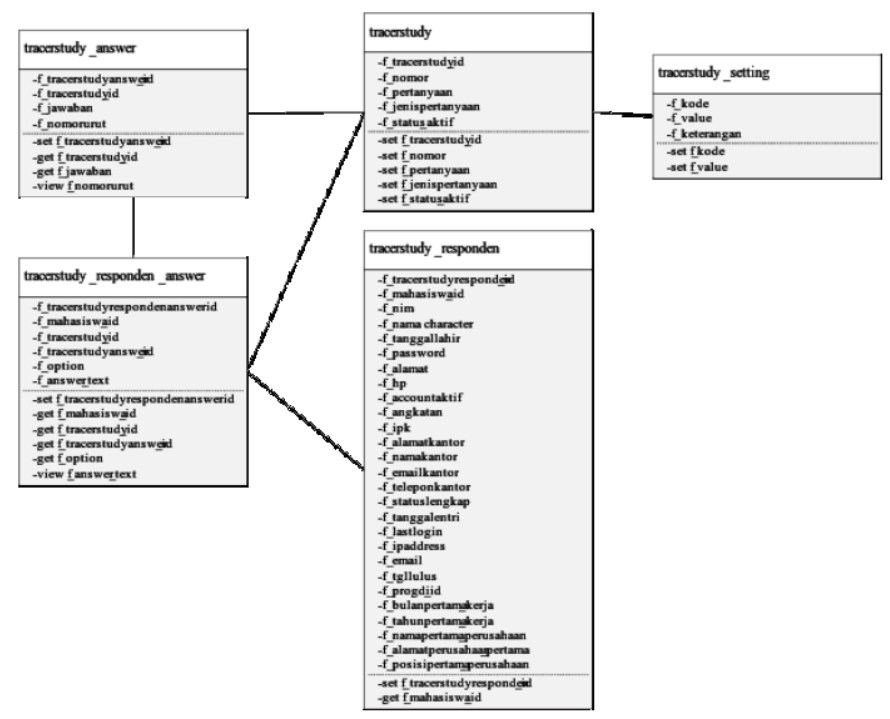

Gambar 8. Class Diagram

\section{Pembuatan source-code dan Hasil Tampilan}

Pada tahapan ini merupakan tahap pembangunan program aplikasi, yaitu dengan membuat kode sumber program dengan menggunakan Bahasa HTML, PHP, dan desain SQL untuk mengambil data.

Adapun pembuatan kode sumber berdasarkan tahapan sebagai berikut

- Kode Sumber SQL

- Kode Sumber HTML dan PHP

\section{Tampilan Pada Website}

Salah satu tampilan rangkuman manajemen tracerstudy dapat dilihat melalui web browser dengan hasil tampilan sebagai berikut : 
Jurnal SISFOKOM, Volume 06, Nomor 01, Maret 2017

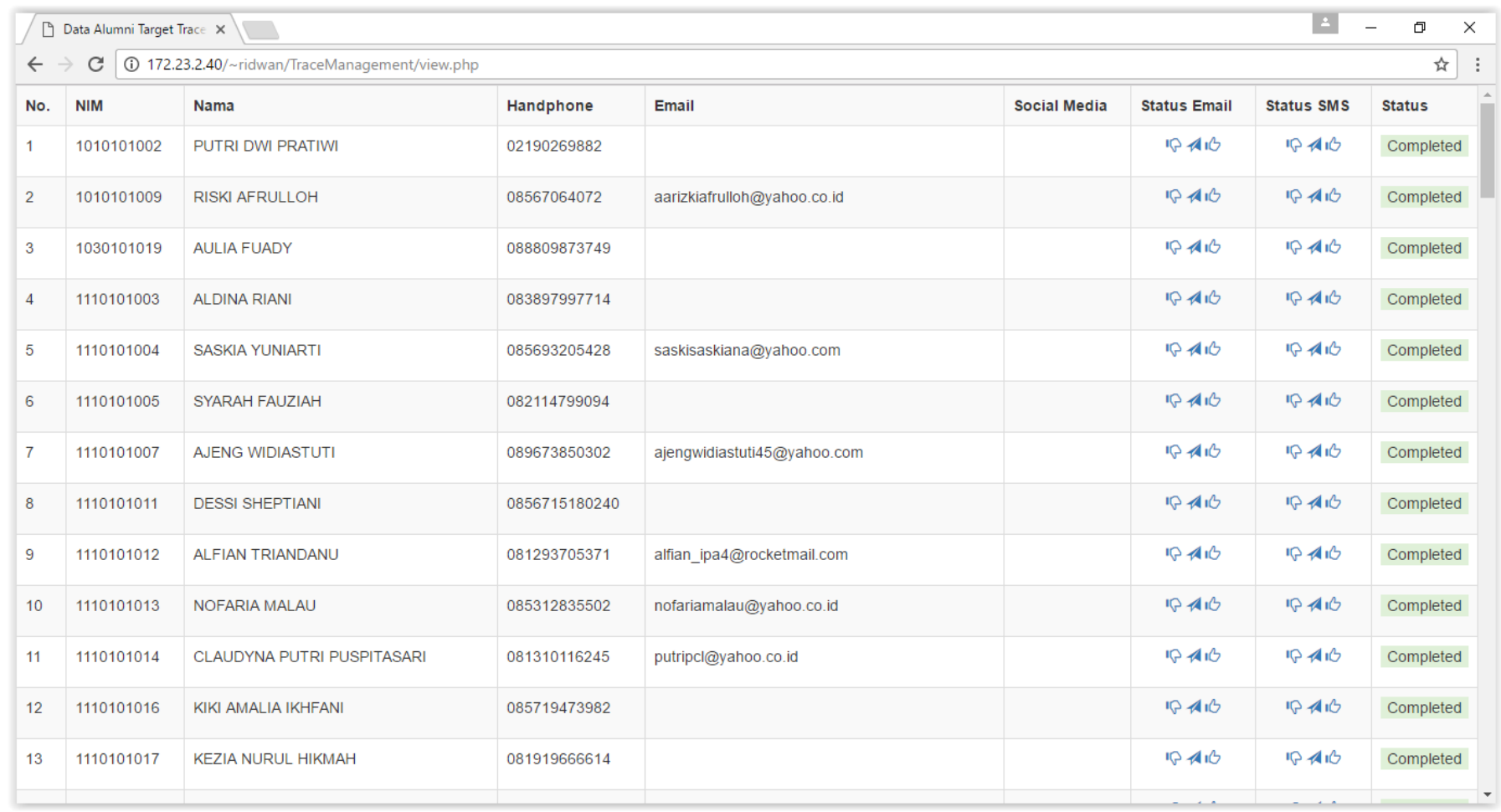

Gambar 9. Tampilan Yang Sudah Isi

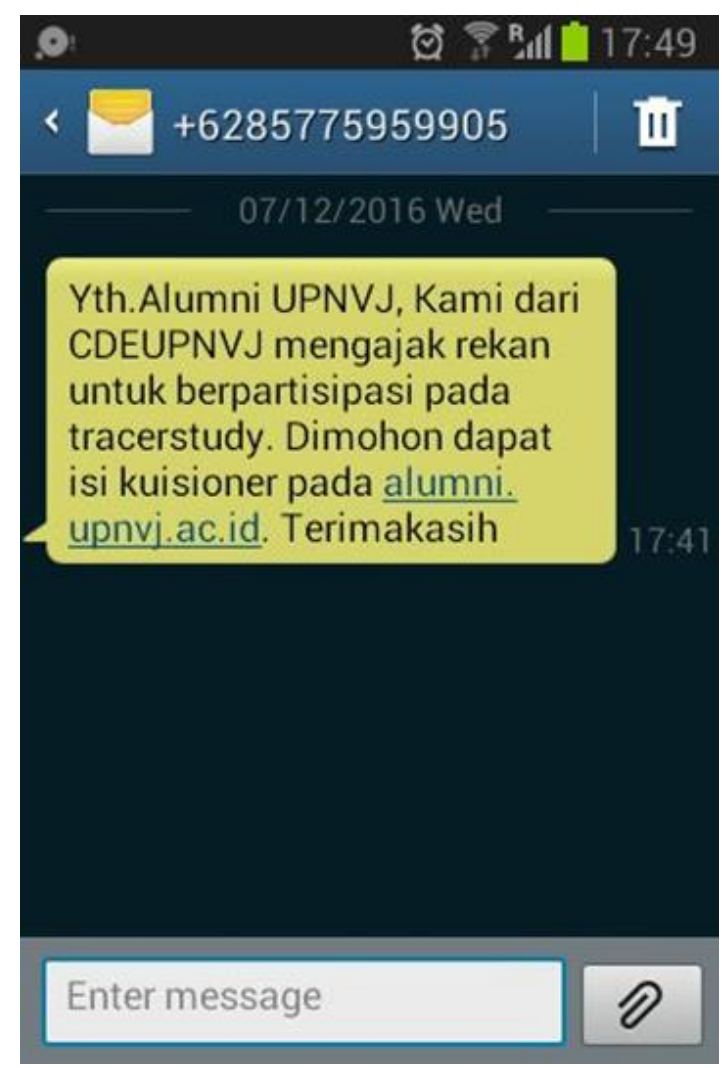

Gambar 10. Contoh SMS Diterima oleh Alumni 


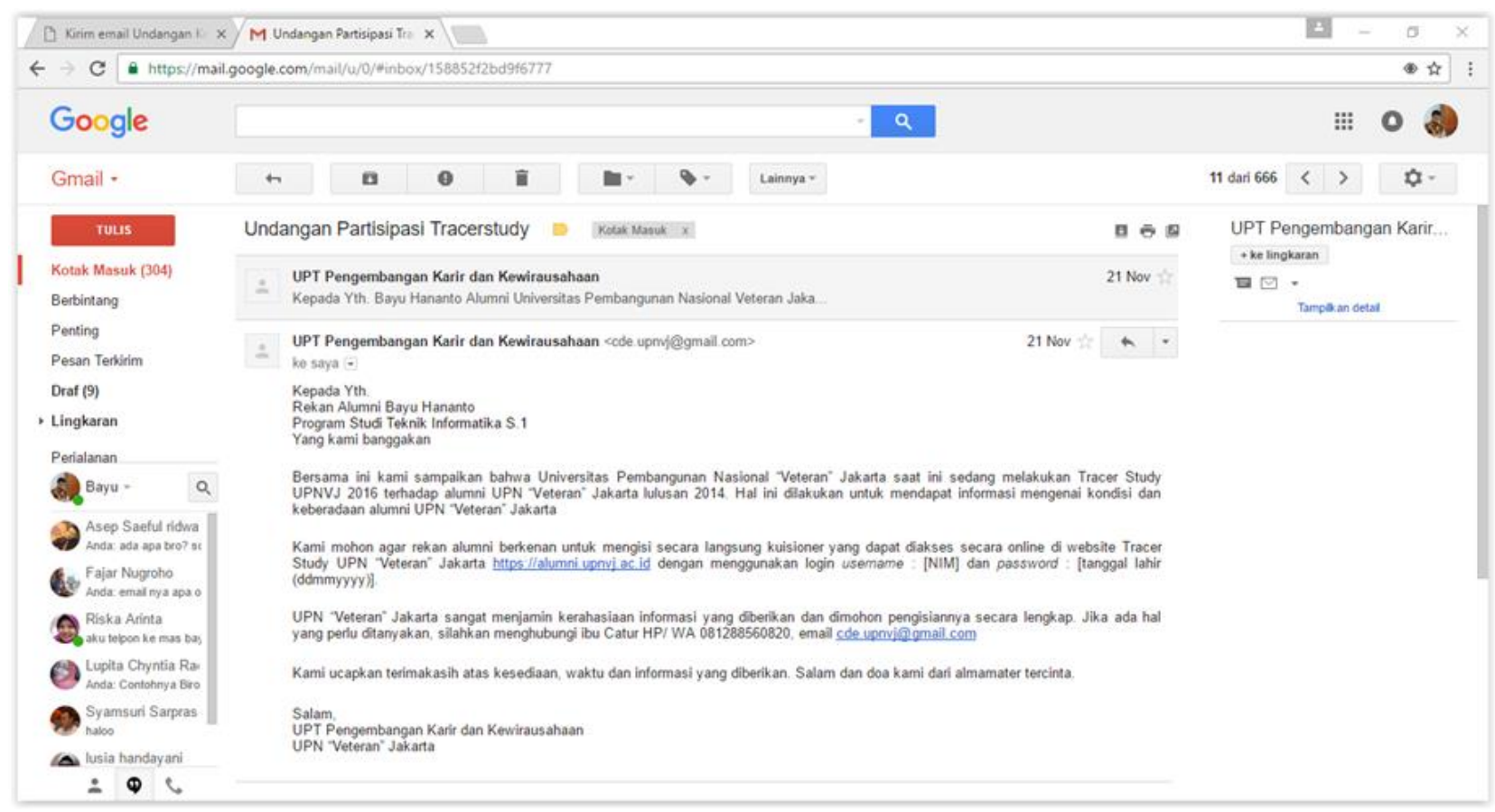

Gambar 11. Contoh Email Diterima Alumni

\section{KESIMPULAN}

Dari pembahasan hasil analisa dan hasil perancangan dapat ditarik kesimpulan bahwa sistem tracerstudy di kampus UPN "Veteran" Jakarta belum optimal disebabkan teknik penyebaran undangan untuk mengisi kuisioner yang belum maksimal. Maka untuk mengoptimalkan hasil, pada penelitian ini menghasilkan suatu sistem terintegrasi dari pangkalan data akademik utama yaitu unisyss dan pangkalan data alumni yang pada penelitian ini dibangun baru.

Kemudian dibangun suatu sistem penyebaran undangan yang massif dengan sistem email blast yang dalam penelitian ini dicoba mengirim email sebanyak 920 alamat email. Berikutnya menggunakan sms bulk yang dikirimkan sms undangan untuk mengisi kuisioner yang pada penelitian ini dicoba dikirimkan 721 sms kepada alumni. Dua tahapan tersebut merupakan tahapan utama dalam pengiriman undangan. Tahap tambahan dalam penelitian ini adalah manajemen telepon terhadap alumni yang belum mengisi survey setelah dikirim email dan sms.

\section{SARAN}

Penelitian ini masih memerlukan penelitian tingkat lanjut, dimana pengolahan data alumni tidak dapat dilaksanakan dalam waktu singkat, maka diperlukan penyempurnaan dari segi SOP (standar operasional prosedur) dan lainnya mengenai pelaksaan tracerstudy. Diperlukan kajian tentang validitas data yang diisikan oleh responden sehingga hasil dari sistem ini mampu memberikan suatu penilaian yang objektif terhadap tujuan dari program tracerstudy itu sendiri dalam menilai tingkat keberhasil universitas.

\section{DAFTAR PUSTAKA}

[1] Ajireswara, Anindito. 2011. Penggunaan Kerangka SDLC dalam Mengembangkan Databas Managemen System, (Tesis). Bogor: Institut Pertanian Bogor.

[2] Alamsyah. 2011. Sistem Informasi Nilai Siswa Sekolah Dasar Sebagai Penunjang Dalam Pengambilan Keputusan. Jurnal SMARTek, Vol. 9 No. 4. Halaman 287 - 299.

[3] Dennis, Alan, at.al. 2009. "Systems Analysis and Design with UML 3rd Edition". John Wiley \& Sons, Inc.

[4] Hartadi, Lupiyo. 2012. Analisis Dan Pengembangan Sistem Informasi Akademik Siswa Berbasis Web Menggunakan PHP Dan MySQL Di SMA N 1 Tayu. (Skripsi). Fakultas Teknik Universias Negeri Yogyakarta.

[5] Jogiyanto, H. M. 2005. Analisis dan Desain Sistem Informasi: Pendekatan Terstruktur Teori dan Praktik Aplikasi Bisnis. Jogyakarta: Andi.

[6] Kadir, Abdul. 2013. "Pengenalan Sistem Informasi”, Andi Offset, Yogyakarta.

[7] Mansur, Kasmawi. 2012. Perancangan Sistem Informasi Sekolah Tingkat Sltp Dinas Pendidikan Kabupaten Bengkalis Berbasis Web. Jurnal Inovtek Volume 2, No Halaman 119-128.

[8] Nugrahaeni, Catur. 2016. Pengembangan Sistem Perpustakaan Terintegrasi Pada Universitas Pembangunan Nasional "Veteran” Jakarta. Jurnal Ilmu Komputer, Vol. 1 - No. 1 Halaman 13 - 27. 